Check for updates

Cite this: RSC Adv., 2017, 7, 40119

\title{
Graphene oxide scroll meshes encapsulated Ag nanoparticles for humidity sensing $\dagger$
}

\author{
Yang Liu, Lin Wang, Hao Zhang, Feirong Ran, Peng Yang and Hai Li (iD)* \\ Ag nanoparticles were firstly encapsulated into graphene oxide (GO) scrolls to form GO-Ag scrolls by \\ a molecular combing method. Horizontally and perpendicularly aligned GO-Ag scrolls were then crossly \\ stacked by a dry transfer method to form GO-Ag scroll meshes. After being reduced by hydrazine, the \\ device based on reduced GO-Ag ( $\mathrm{rGO}-\mathrm{Ag}$ ) scroll meshes shows 3 orders of magnitude higher response \\ in humidity sensing compared to that of reduced GO ( $\mathrm{rGO}$ ) scroll meshes. In addition, $\mathrm{rGO}-\mathrm{Ag}$ scroll \\ meshes-based device shows good humidity sensing stability in ambient conditions over a month.
}

Received 2nd June 2017

Accepted 8th August 2017

DOI: $10.1039 / \mathrm{c} 7 \mathrm{ra06177c}$

rsc.li/rsc-advances structures and high compatibility. Currently, many materials have been used for highly sensitive humidity detection, such as $\mathrm{WS}_{2},{ }^{36-38} \mathrm{MoS}_{2},{ }^{39,40}$ zinc oxide, ${ }^{41,42}$ aluminium oxide, ${ }^{23,43}$ and organic materials. ${ }^{\mathbf{4 4}, 45}$ Recently, graphene oxide and its composite have been widely reported for humidity sensing with good repeatability and response..$^{22,26,46-51}$ However, the stability and sensitivity of humidity sensors are still in concern for practical applications. Therefore, it is highly desirable to develop sensitive humidity sensors with long term stability.

Recently, GO scroll meshes were fabricated by cross-stacking GO scroll in combination of molecular combing and dry transfer technique. ${ }^{\mathbf{6 1 1}, 12,52}$ We found that GO scroll meshes can be used as transparent and flexible electrodes and show excellent electrical stability after being bent more than 10000 cycles. In this work, Ag NPs were firstly encapsulated into GO scroll to form $\mathrm{GO}-\mathrm{Ag}$ scroll by molecular combing. Atomic force microscopy (AFM), scanning electron microscopy (SEM) and transmission electron microscopy (TEM) characterization indicate Ag NPs were uniformly encapsulated into GO scroll. GO-Ag scroll meshes with size up to $\mathrm{cm}$ scale were then prepared by dry transfer method. After being reduced by hydrazine, reduced GO-Ag (rGO-Ag) scroll meshes were used for humidity sensing. Compared to rGO scroll meshes, rGO-Ag scroll meshes show much better linear response for humidity.

As shown in Scheme 1, Ag NPs were deposited on GO (GO-Ag) sheet by hydrothermal method. Then GO-Ag sheets were transformed into GO-Ag scrolls array by molecular combing (step 1). GO-Ag scroll meshes were fabricated through crossly stacking GO-Ag scrolls array by dry transfer method (step 2).

AFM was firstly used to characterize GO and GO-Ag sheets. As shown in Fig. 1A, the height of GO sheet is $1.08 \mathrm{~nm}$, indicating it is single layer GO. After Ag NPs were deposited on GO sheet, the height of GO-Ag sheet is increased up to $\sim 6 \mathrm{~nm}$ (Fig. 1B). As shown in Fig. 1C, Ag NPs were uniformly distributed on GO sheet. The mean height of Ag NPs is $6.25 \pm 0.5 \mathrm{~nm}$ (Fig. 1D). UV-vis spectrometer has been utilized to characterize
Key Laboratory of Flexible Electronics (KLOFE), Institute of Advanced Materials (IAM), Jiangsu National Synergetic Innovation Center for Advanced Materials (SICAM), Nanjing Tech University (Nanjing Tech), 30 South PuZhu Road, Nanjing 211816, China.E-mail:iamhli@njtech.edu.cn

$\dagger$ Electronic supplementary information (ESI) available. See DOI: $10.1039 / \mathrm{c} 7 \mathrm{ra06177c}$ 


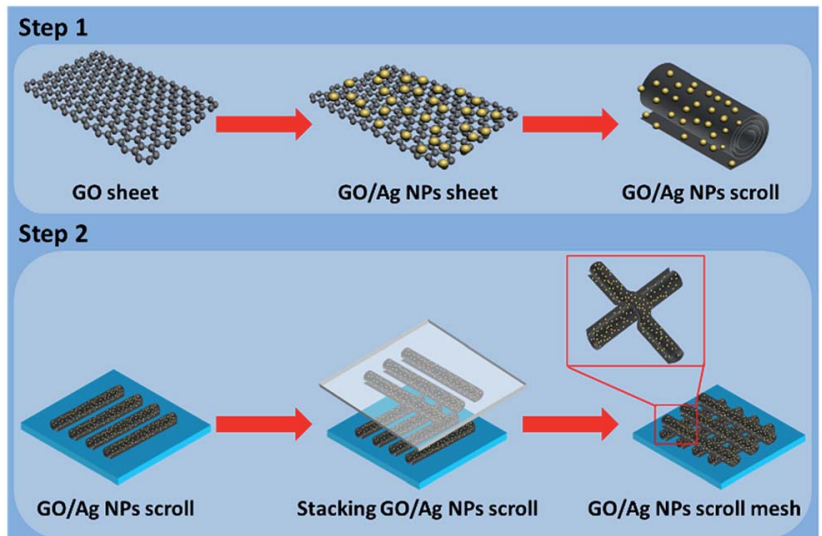

Scheme 1 Fabrication of GO-Ag Scroll meshes. Step 1, GO-Ag scroll was prepared by molecular combing Ag NPs decorated GO sheet Step 2, GO-Ag scroll meshes were fabricated by crossly stacking $\mathrm{GO}-$ Ag scroll array.

as-prepared GO and GO-Ag sheets. Two characteristic peaks were observed in the UV-vis spectrum of GO sheet (Fig. S1 in ESI $\dagger$ ). The peak at $232 \mathrm{~nm}$ is attributed to the $\pi-\pi^{*}$ transitions of the aromatic C-C bonds and a shoulder at $300 \mathrm{~nm}$ is derived from the $n-\pi^{*}$ transitions of the $\mathrm{C}=\mathrm{O}$ bonds. ${ }^{18,21}$ The formation of Ag NPs on GO sheet was confirmed by the strong peak around $400 \mathrm{~nm}$, which is attributed to the surface plasmon resonance of $\mathrm{Ag}$ NPs, as shown in the UV-vis spectrum of GO-Ag nanocomposite (Fig. S1 in ESI†).

GO-Ag scroll was then prepared by molecular combing GO-Ag sheet on octadecyltrimethoxysilane-modified $\mathrm{SiO}_{2}$ (OTS$\mathrm{SiO}_{2}$ ), which is hydrophobic. ${ }^{6}$ As shown in Fig. 2A, the height of
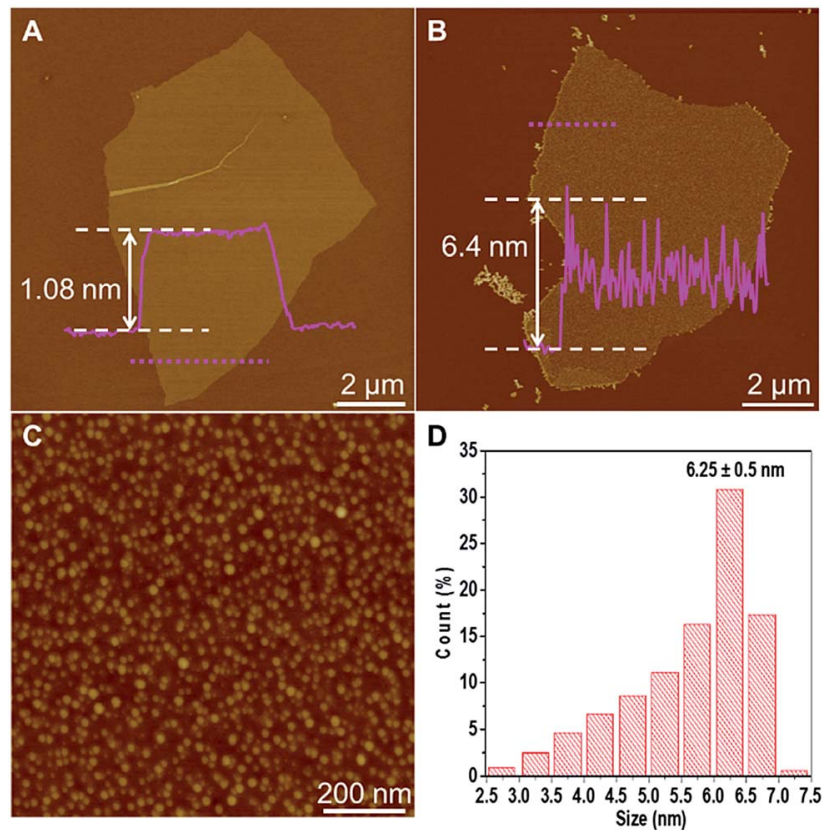

Fig. 1 AFM images of (A) GO and (B) GO-Ag sheets, respectively. (C) Magnified image of (B). (D) Height distribution of Ag NPs.

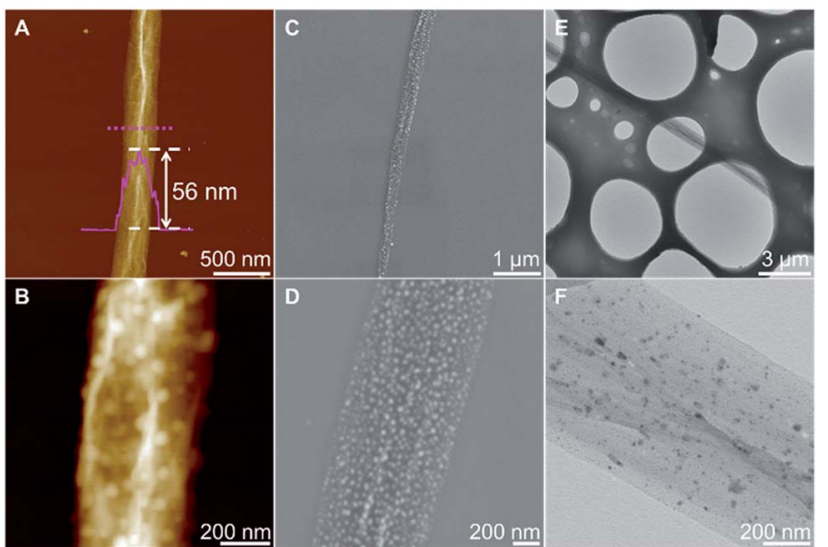

Fig. 2 (A) AFM, (C) SEM and (E) TEM images of GO-Ag scroll, respectively. ( $B, D$ and $F$ ) Magnified images of (A), (C) and (E), respectively.

GO-Ag scroll is $\sim 56 \mathrm{~nm}$, which is a bit higher than that of GO scroll (Fig. S2 in ESI†). In addition, GO-Ag scroll usually has a width less than $1 \mu \mathrm{m}$. Ag NPs can be clearly observed in magnified AFM image (Fig. 2B). In order to further investigate the structure of GO-Ag scroll, SEM and TEM were employed. The magnified SEM and TEM images further confirm that dense $\mathrm{Ag}$ NPs were homogeneously distributed on GO surface (Fig. 2C-F and S3 in ESI $\dagger$ ), which is in good agreement with AFM measurement, indicating successful encapsulation of $\mathrm{Ag}$ NPs into GO scroll.

GO-Ag scroll meshes were fabricated by using dry transfer method as previously reported. ${ }^{\mathbf{1 1}}$ Firstly, horizontally and perpendicularly aligned GO-Ag scrolls arrays were prepared using molecular combing method (Fig. S4 in ESI†), respectively. We found that the concentration of GO-Ag solution plays an important role in determining the morphology of GO-Ag scroll. Long straight GO-Ag scrolls were observed on $\mathrm{OTS}_{-} \mathrm{SiO}_{2}$ when concentration is less than $0.1 \mathrm{mg} \mathrm{mL}^{-1}$, while dendritic $\mathrm{GO}-\mathrm{Ag}$ scrolls were prepared as the concentration is higher than $0.1 \mathrm{mg} \mathrm{mL}^{-1}$ (Fig. S5 in ESI $\dagger$ ). Then horizontally aligned GO-Ag scrolls array was lift off from substrate with the aid of PMMA and PDMS (see Experimental section in ESI $\dagger$ ). The lifted horizontally aligned GO-Ag scrolls array was then stacked on perpendicularly aligned GO-Ag scrolls array. After PDMS and PMMA film were removed, GO-Ag scroll meshes with size up



Fig. 3 (a) Photograph of a GO-Ag scroll meshes-based device with size up to $\mathrm{cm}$ scale on $\mathrm{SiO}_{2} / \mathrm{Si}$ substrate. (b) Optical microscopy image of GO-Ag scroll meshes shown in the dashed box in (a). (c) Magnified optical microscopy image of $\mathrm{GO}-\mathrm{Ag}$ scroll meshes shown in the dashed box in (b). 



Fig. 4 (A) Time-dependent response and recovery curve of rGO scroll meshes-based device at different humidity. (B) Relationship between the response and relative humidity of $\mathrm{rGO}$ scroll meshes-based device. (C) Time-dependent response and recovery curve of $\mathrm{rGO}-\mathrm{Ag}$ scroll meshes-based device at different humidity. (D) Relationship between the response and relative humidity of $\mathrm{rGO}-\mathrm{Ag}$ scroll meshes-based device.

to cm scale was formed. Similarly, GO scroll meshes with size up to $\mathrm{cm}$ scale was also prepared by this method.

It is known that encapsulating nanomaterials into GNSs can further improve their performance in the fields of supercapacitor, lithium-ion battery and sensor. ${ }^{2-6,53,54}$ Herein, we tried to investigate the performance of $\mathrm{GO}-\mathrm{Ag}$ scroll meshes on humidity sensing.

After GO and GO-Ag scroll meshes were reduced by hydrazine at $80^{\circ} \mathrm{C}$ for $24 \mathrm{~h}, \mathrm{Ag}$ paste was deposited on two corners of reduced GO (rGO) and $\mathrm{GO}-\mathrm{Ag}$ ( $\mathrm{rGO}-\mathrm{Ag}$ ) scroll meshes as electrodes to obtain devices. Fig. 3a shows the photograph of rGO-Ag scroll meshes-based device on $\mathrm{SiO}_{2} / \mathrm{Si}$ substrate. Magnified optical microscopy images show that GO-Ag scrolls were well cross-linked (Fig. $3 \mathrm{~b}$ and $\mathrm{c}$ ). The conductivities of GO and GO-Ag scroll meshes-based devices were firstly checked by measuring their $I-V$ characteristics. By applying voltage from 0 to $0.5 \mathrm{~V}$, both rGO and rGO-Ag scroll meshes-based devices showed linear relationship, indicating the well-ohmic contact formed between the electrode and the mesh (Fig. S6 in ESI $\dagger$ ). Moreover, the slope of rGO-Ag scroll meshes-based device was larger compared to that of rGO scroll meshes-based device, indicating the encapsulation of $\mathrm{Ag}$ NPs can increase the conductivity of GO scroll meshes.
The humidity sensing measurement on $\mathrm{rGO}$ and $\mathrm{rGO}-\mathrm{Ag}$ scroll meshes-based devices was carried out at room temperature. The switching $\mathrm{RH}$ test is performed through exposure/ recovery cycles at $11 \%, 33 \%, 52 \%, 75 \%$ and $97 \%$ relative humidity $(\mathrm{RH})$, respectively. The response of the sensors was defined as: response $=I_{\mathrm{RH}}-I_{\mathrm{N}_{2}} / I_{\mathrm{N}_{2}},{ }^{39,54,55}$ where $I_{\mathrm{RH}}$ and $I_{\mathrm{N}_{2}}$ are the currents through the device in presence of different humidity and dried $\mathrm{N}_{2}$, respectively. The current through the device in presence of ambient air acts as the baseline. Each humidity response is carried out by an exposure interval of $60 \mathrm{~s}$ followed by purging with compressed dry $\mathrm{N}_{2}$ to achieve a stable baseline. Fig. 4A shows the real-time response of the rGO scroll meshes-based device exposed to different RH. Although the response keeps increasing as the humidity increased, the response value is too small for practical application. Fig. 4B shows the relationship between the response and relative humidity of rGO scroll meshes-based device. The linear regression coefficient, $R^{2}$, of rGO scroll meshes-based device is only 0.902 . The response time and recovery time of rGO scroll meshes-based device are $\sim 15 \mathrm{~s}$ and $\sim 18 \mathrm{~s}$, respectively. As shown in Fig. 4C, the rGO-Ag scroll meshes sensor exhibited quite excellent response towards the humidity in a range of 11-97\% RH. The response of rGO-Ag scroll meshes sensor reaches 908 even exposed to 11\% RH, indicating its high sensitivity for humidity sensing. As the humidity increased from $11 \%$ to $97 \% \mathrm{RH}$, the response is also increased from 908 to 1243. In addition, the linear regression coefficient of the rGO-Ag scroll meshes sensor, $R^{2}$, is 0.9986 (Fig. 4D), indicating its good linear behaviour for humidity sensing. The response time and recovery time of $\mathrm{rGO}-\mathrm{Ag}$ scroll meshes-based device are $\sim 50 \mathrm{~s}$ and $\sim 13 \mathrm{~s}$, respectively. Based on aforementioned results, it is obvious that the $\mathrm{rGO}-\mathrm{Ag}$ scroll meshes sensor showed not only excellent response but also good linear behaviour for humidity sensing compared to those of rGO scroll meshes sensor. Table 1 shows the humidity sensing performance of our rGO-Ag scroll meshes sensor in comparison with previously reported works based on graphene oxide and its composite. It indicates that $\mathrm{rGO}-\mathrm{Ag}$ scroll meshes are promising for humidity sensing.

In order to demonstrate the different sensitivities of rGO and rGO-Ag scroll meshes, the response curves of rGO and $\mathrm{rGO}-\mathrm{Ag}$ scroll meshes-based devices towards same relative humidity were measured (Fig. S6 in ESI $\dagger$ ). Both rGO and rGO-Ag scroll meshes exhibited immediate response towards humid air. However, rGO-Ag scroll meshes-based device exhibits 3 orders

Table 1 Comparison of humidity sensing performance of GO and its composites reported in this work and previous works

\begin{tabular}{|c|c|c|c|c|}
\hline Sensing material & Sensor type & Humidity & Response & Ref. \\
\hline Graphene oxide & Capacitive & $0-100 \% \mathrm{RH}$ & $7680 \mathrm{PF} / \% \mathrm{RH}$ & 22 \\
\hline GO/PDDA & Resistive & $11-97 \% \mathrm{RH}$ & $8.69-37.43 \%$ & 24 \\
\hline $\mathrm{GO} / \mathrm{MoS}_{2}$ & Resistive & $35-85 \% \mathrm{RH}$ & $3-1600$ & 25 \\
\hline GO silicon bi-layer & Stress & $10-98 \% \mathrm{RH}$ & $28.02 \mu \mathrm{V} / \% \mathrm{RH}$ & 46 \\
\hline Defect graphene & Capacitive & $3-30 \% \mathrm{RH}$ & $0.27-3.3 \%$ & 49 \\
\hline Graphene oxide & Impedance & $11-95 \% \mathrm{RH}$ & $0.9-33.254 \%$ & 54 \\
\hline rGO-Ag scroll meshes & Resistive & $11-97 \% \mathrm{RH}$ & $908-1243$ & This work \\
\hline
\end{tabular}





Fig. 5 (A) Response contrast between rGO scroll mesh and $\mathrm{rGO}-\mathrm{Ag}$ scroll mesh at $75 \% \mathrm{RH}$. (B) The stability of $\mathrm{KGO}-\mathrm{Ag}$ scroll mesh at $33 \%$, $75 \%$ and $97 \% \mathrm{RH}$, respectively.

of magnitude higher than that of rGO scroll meshes-based device (Fig. 4A, C and S6 in ESI $\dagger$ ). The excellent sensitivity of rGO-Ag scroll meshes can be attributed to the encapsulation of $\mathrm{Ag}$ nanoparticles, which enhances the conductivity of rGO-Ag scroll meshes and further contributes to the good current change before and after being exposed to humid air.

Interestingly, our rGO-Ag scroll meshes-based device also shows good long term stability in comparison with previously reported humidity sensors. ${ }^{51,56}$ After being reduced by hydrazine and exposed to humid air for the first cycle of humidity response measurement, the humidity sensing performance of rGO-Ag scroll meshes-based device was measured after being stored in ambient condition for 1, 5, 10, 20 and 30 days, respectively. As shown in Fig. 5, the response of the sensor almost has no degradation for humidity sensing measurement at $33 \%, 75 \%$ and $97 \% \mathrm{RH}$, implying the potential practical application of rGO-Ag scroll meshes in humidity sensing.

\section{Conclusions}

In conclusion, we have presented a facile one-pot, cost-effective method to synthesize rGO/AgNPs scroll meshes. The rGO/ AgNPs scroll meshes, which take advantage of GO or rGO as a template was achieved without any other surfactant or reducing agent. The humidity sensing properties of rGO/AgNPs scroll meshes were investigated when exposed to varying $\mathrm{RH}$ at room temperature. Moreover, the sensor show excellent conductivity as current sensor and exhibit notable humidity sensor performance toward different humidity level with outstanding stability and linearity at ambient environment. In addition, the possible mechanism for humidity sensing of $\mathrm{rGO} /$ AgNPs was also investigated in this study. It is suggested that the humidity response of the present sensor is ascribed to cooperative effect of both the electron and ion conductivity.

\section{Conflicts of interest}

There are no conflicts to declare.

\section{Acknowledgements}

This work was supported by the National Natural Science Foundation of China (Grant No. 21571101 and 51528201), the Natural Science Foundation of Jiangsu Province in China (Grant
No. BK20161543), and the Natural Science Foundation of the Jiangsu Higher Education Institutions of China (Grant No. 15KJB430016).

\section{Notes and references}

1 J. Zhao, B. Yang, Z. Zheng, J. Yang, Z. Yang, P. Zhang, W. Ren and X. Yan, ACS Appl. Mater. Interfaces, 2014, 6, 9890-9896.

2 G. Mpourmpakis, E. Tylianakis and G. E. Froudakis, Nano Lett., 2007, 7, 1893-1897.

3 X. Xie, L. Ju, X. F. Feng, Y. H. Sun, R. F. Zhou, K. Liu, S. S. Fan, Q. Q. Li and K. L. Jiang, Nano Lett., 2009, 9, 2565-2570.

4 T. Fan, W. Zeng, Q. Niu, S. Tong, K. Cai, Y. Liu, W. Huang, Y. Min and A. J. Epstein, Nanoscale Res. Lett., 2015, 10, 192.

5 M. V. Savoskin, V. N. Mochalin, A. P. Yaroshenko, N. I. Lazareva, T. E. Konstantinova, I. V. Barsukov and I. G. Prokofiev, Carbon, 2007, 45, 2797-2800.

6 H. Li, J. Wu, X. Y. Qi, Q. Y. He, C. Liusman, G. Lu, X. Z. Zhou and H. Zhang, Small, 2013, 9, 382-386.

7 Y. Gao, X. Q. Chen, H. Xu, Y. L. Zou, R. P. Gu, M. S. Xu, A. K. Y. Jen and H. Z. Chen, Carbon, 2010, 48, 4475-4482.

8 Y. Liu, Y. Xia, H. Yang, Y. Zhang, M. Zhao and G. Pan, Nanotechnology, 2013, 24, 235401.

9 X. L. Li, Y. L. Zhang, T. T. Li, N. Z. Qi, H. Y. Li and J. M. Huang, J. Power Sources, 2014, 268, 372-378.

10 B. J. Yang, J. P. Zhao, J. T. Chen, M. He and S. Xu, RSC Adv., 2015, 5, 57906-57911.

11 J. Wu, J. Yang, Y. Huang, H. Li, Z. X. Fan, J. Q. Liu, X. D. Cao, X. Huang, W. Huang and H. Zhang, Adv. Mater. Technol., 2017, 2, 1066231.

12 J. Wu, H. Li, X. Y. Qi, Q. Y. He, B. X. Xu and H. Zhang, Small, 2014, 10, 2239-2244.

13 S. Stankovich, D. A. Dikin, G. H. B. Dommett, K. M. Kohlhaas, E. J. Zimney, E. A. Stach, R. D. Piner, S. T. Nguyen and R. S. Ruoff, Nature, 2006, 442, 282-286.

14 C. Lee, X. D. Wei, J. W. Kysar and J. Hone, Science, 2008, 321, 385-388.

15 C. Gomez-Navarro, R. T. Weitz, A. M. Bittner, M. Scolari, A. Mews, M. Burghard and K. Kern, Nano Lett., 2007, 7, 3499-3503.

16 M. S. Zhu, P. L. Chen and M. H. Liu, ACS Nano, 2011, 5, 45294536.

17 J. Xu, S. Z. Gub and B. Lu, RSC Adv., 2015, 5, 72046-72050.

18 Y. L. Li, X. J. Zhao, P. P. Zhang, J. Ning, J. F. Li, Z. Q. Su and G. Wei, J. Mater. Chem. C, 2015, 3, 4126-4133.

19 X. Z. Zhou, X. Huang, X. Y. Qi, S. X. Wu, C. Xue, F. Y. C. Boey, Q. Y. Yan, P. Chen and H. Zhang, J. Phys. Chem. C, 2009, 113, 10842-10846.

20 B. Adhikari and A. Banerjee, Mater. Chem. Phys., 2013, 139, 450-458.

21 K. S. Hui, K. N. Hui, D. A. Dinh, C. H. Tsang, Y. R. Cho, W. Zhou, X. T. Hong and H. H. Chun, Acta Mater., 2014, 64, 326-332.

22 R. Guo, W. Tang, C. T. Shen and X. Wang, Comput. Mater. Sci., 2016, 111, 289-293.

23 Y. Kim, B. Jung, H. Lee, H. Kim, K. Lee and H. Park, Sens. Actuators, B, 2009, 141, 441-446. 
24 D. Z. Zhang, J. Tong and B. K. Xia, Sens. Actuators, B, 2014, 197, 66-72.

25 D. Burman, R. Ghosh, S. Santra and P. K. Guha, RSC Adv., 2016, 6, 57424-57433.

26 S. Ghosh, R. Ghosh, P. K. Guha and T. K. Bhattacharyya, IEEE Trans. Nanotechnol., 2015, 14, 931-937.

27 S. Akita, H. Sasaki, K. Watanabe and A. Seiki, Sens. Actuators, $B$, 2010, 147, 385-391.

28 F. J. Arregui, Y. J. Liu, I. R. Matias and R. O. Claus, Sens. Actuators, B, 1999, 59, 54-59.

29 F. X. Liang, L. B. Luo, C. K. Tsang, L. X. Zheng, H. Cheng and Y. Y. Li, Mater. Res. Bull., 2012, 47, 54-58.

30 S. H. Song, H. H. Yang, C. H. Han, S. D. Ko, S. H. Lee and J. B. Yoon, Appl. Phys. Lett., 2012, 100, 101603.

31 R. Rimeika, D. Čiplys, V. Poderys, R. Rotomskis and M. S. Shur, Sens. Actuators, B, 2009, 137, 592-596.

32 Y. Li, P. Li, M. Yang, S. Lei, Y. Chen and X. Guo, Sens. Actuators, B, 2010, 145, 516-520.

33 W. P. Xuan, M. He, N. Meng, X. L. He, W. B. Wang, J. K. Chen, T. J. Shi, T. Hasan, Z. Xu, Y. Xu and J. K. Luo, Sci. Rep., 2014, 4, 7206.

34 A. De Luca, S. Santra, R. Ghosh, S. Z. Ali, J. W. Gardner, P. K. Guha and F. Udrea, Nanoscale, 2016, 8, 4565-4572.

35 S. Borini, R. White, D. Wei, M. Astley, S. Haque, E. Spigone, N. Harris, J. Kivioja and T. Ryhanen, ACS Nano, 2013, 7, 11166-11173.

36 Y. H. Luo, C. Y. Chen, K. Xia, S. H. Peng, H. Y. Guan, J. Y. Tang, H. U. Lu, J. H. Yu, J. Zhang, Y. Xiao and Z. Chen, Opt. Express, 2016, 24, 8956-8966.

37 H. Y. Guan, K. Xia, C. Y. Chen, Y. H. Luo, J. Y. Tang, H. H. Lu, J. H. Yu, J. Zhang, Y. C. Zhong and Z. Chen, Opt. Mater. Express, 2017, 7, 1686-1696.

38 R. K. Jha and P. K. Guha, Nanotechnology, 2016, 27, 475503.

39 D. Burman, R. Ghosh, S. Santra and P. K. Guha, RSC Adv., 2016, 6, 57424-57433.
40 N. Li, X. D. Chen, X. P. Chen, X. Ding and X. Zhao, IEEE Electron Device Lett., 2017, 38, 806-809.

41 Y. S. Zhang, K. Yu, D. S. Jiang, Z. Q. Zhu, H. R. Geng and L. Q. Luo, Appl. Surf. Sci., 2005, 242, 212-217.

42 S. P. Yawale, S. S. Yawale and A. T. Lamdhade, Sens. Actuators, A, 2007, 135, 388-393.

43 S. W. Chen, O. K. Khor, M. W. Liao and C. K. Chung, Sens. Actuators, B, 2014, 199, 384-388.

44 Y. D. Park, B. Kang, H. S. Lim, K. Cho, M. S. Kang and J. H. Cho, ACS Appl. Mater. Interfaces, 2013, 5, 8591-8596.

45 Z. Ahmad, Q. Zafar, K. Sulaiman, R. Akram and K. S. Karimov, Sensors, 2013, 13, 3615-3624.

46 Y. Yao, X. D. Chen, H. H. Guo, Z. Q. Wu and X. Y. Li, Sens. Actuators, B, 2012, 161, 1053-1058.

47 N. Weiß, L. Müller-Meskamp, F. Selzer, L. Bormann, A. Eychmüller, K. Leo and N. Gaponik, RSC Adv., 2015, 5, 19659-19665.

48 T. Nakajima, T. Nakamura and T. Tsuchiya, RSC Adv., 2016, 6, 95342-95348.

49 Q. W. Huang, D. W. Zeng, S. Q. Tian and C. S. Xie, Mater. Lett., 2012, 83, 76-79.

50 Y. Liu and Y. M. Chen, J. Appl. Phys., 2016, 119, 103301103306.

51 B. H. Wee, W. H. Khoh, A. K. Sarker, C. H. Lee and J. D. Hong, Nanoscale, 2015, 7, 17805-17811.

52 H. Li, J. M. T. Wu, X. Huang, Z. Y. Yin, J. Q. Liu and H. Zhang, ACS Nano, 2014, 8, 6563-6570.

53 X. Chen, L. Li, X. Sun, H. G. Kia and H. Peng, Nanotechnology, 2012, 23, 055603.

54 X. Y. Feng, W. F. Chen and L. F. Yan, Sens. Actuators, B, 2015, 215, 316-322.

55 J. F. Feng, X. X. Kang, Q. Y. Zuo, C. Yuan, W. J. Wang, Y. H. Zhao, L. M. Zhu, H. W. Lu and J. Y. Chen, Sensors, 2016, 16, 314.

56 G. H. Lu, L. E. Ocola and J. H. Chen, Appl. Phys. Lett., 2009, 94, 083111. 